\title{
Electrolyte-free gel immersion endoscopic submucosal dissection of gastric lesions
}

Gel immersion endoscopy was developed to secure the visual field during ongoing gastrointestinal bleeding using the viscous rehydration supplement "OS- 1 jelly" (Otsuka Pharmaceutical Factory, Tokushima, Japan) [1]. However, this includes electrolytes and needs replacement with gas or pure water before cauterization using monopolar devices to avoid electrical dispersion [1]. A new, dedicated electrolyte-free gel (Viscoclear; Otsuka Pharmaceutical Factory) allows effective coagulation within the gel [2], enabling usage during endoscopic submucosal dissection (ESD).

With the emergence of new strategies to conquer difficult ESD, the water (or saline) immersion technique [3] and pocket-creation method have become popular [4]. Inside the "pocket" during intraprocedural bleeding, gel immersion endoscopy easily secures the visual field with a small amount of gel [5].

We present two cases of ESD using gel immersion endoscopy ( Video 1 ). In the first case with intraprocedural bleeding, we injected electrolyte-free gel via the accessory channel through the Bioshield irrigator (US Endoscopy, Mentor, Ohio, USA) to secure the visual field. The bleeding point was identified and coagulated with hemostatic forceps within the gel ( Fig. 1).

In the second case, we demonstrate the combination of gel and saline immersion ESD. Saline immersion ESD is reportedly advantageous because of buoyancy; however, rapid reduction of visualization due to minor bleeding, trapped gas within the hood, or inefficient coagulation due to electrical dispersion can be challenging [3]. Gel immersion ESD maintains a clear visual field, especially in cases with the lesion on the lower side of gravity, where dirty water and blood collect easily. The viscosity of the gel prevents the direct flow of gas bubbles

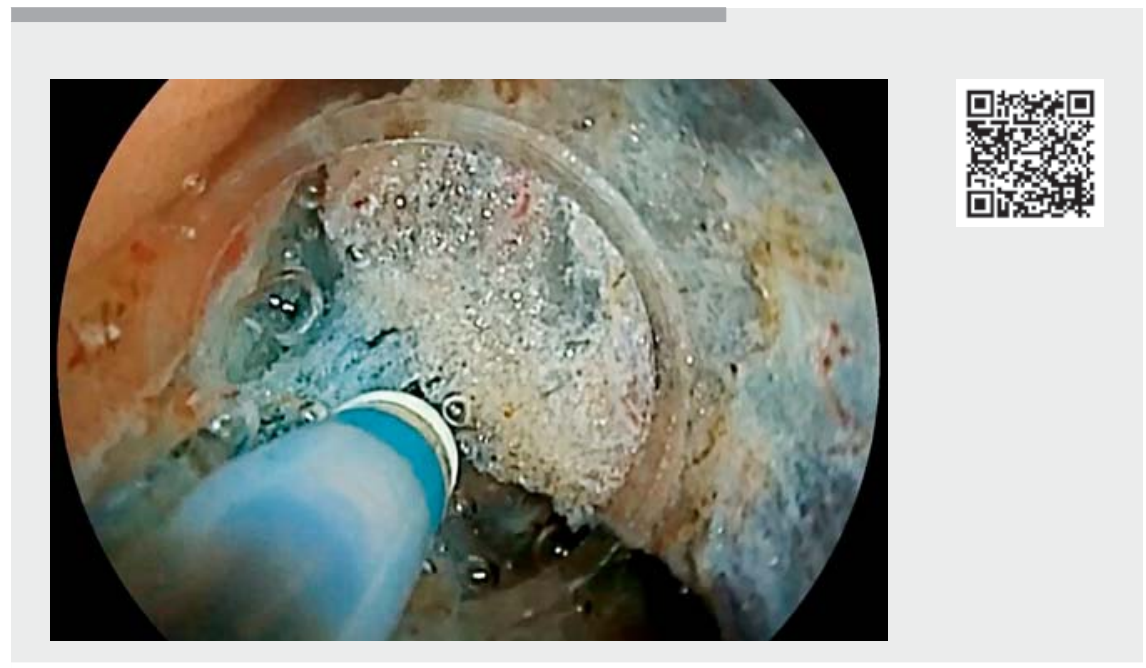

$\checkmark$ Video 1 Gastric gel immersion in endoscopic submucosal dissection with a new, dedicated electrolyte-free gel.
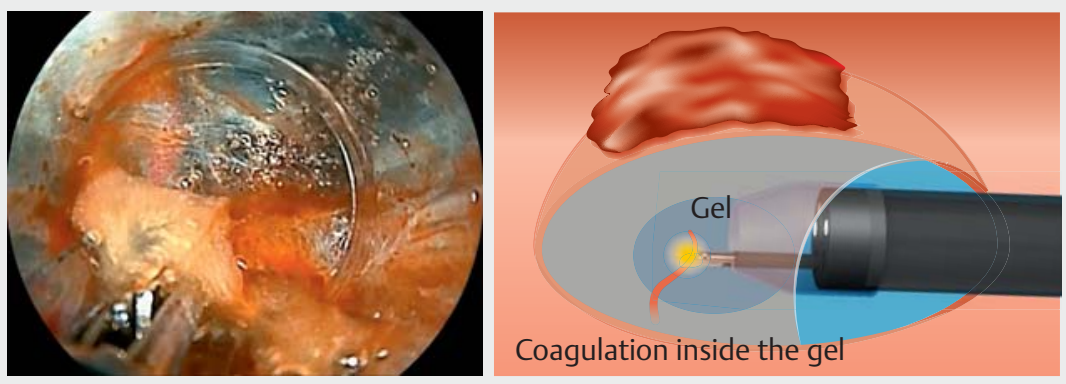

-Fig. 1 Intraprocedural hemostasis with a new, dedicated electrolyte-free gel during the pocket-creation method of endoscopic submucosal dissection. After grasping the bleeding point with hemostatic forceps, direct coagulation with monopolar hemostatic forceps was performed.

into the tip of the hood, and we can easily remove them by injecting a small amount of additional gel ( $>$ Fig. 2 ).

Gel immersion ESD has the advantages of obtaining sufficient traction by buoyancy, maintaining a clear visual field regardless of lesion location, and enabling precision coagulation for hemostasis.

Endoscopy_UCTN_Code_TTT_1AO_2AG

\section{Competing interests}

Hironori Yamamoto has patents for ESD devices and double-balloon endoscopy produced by Fujifilm Corp. He is also a consultant and has received honoraria, grants, and royalties from Fujifilm Corp. Hiroyuki Osawa has received honoraria and grants from Fujifilm Corp. Tomonori Yano has patents for the dedicated electrolyte-free gel. Yoshimasa Miura and Tomonori Yano have received honoraria from Fujifilm Corp. The remaining authors declare that they have no conflict of interest. 

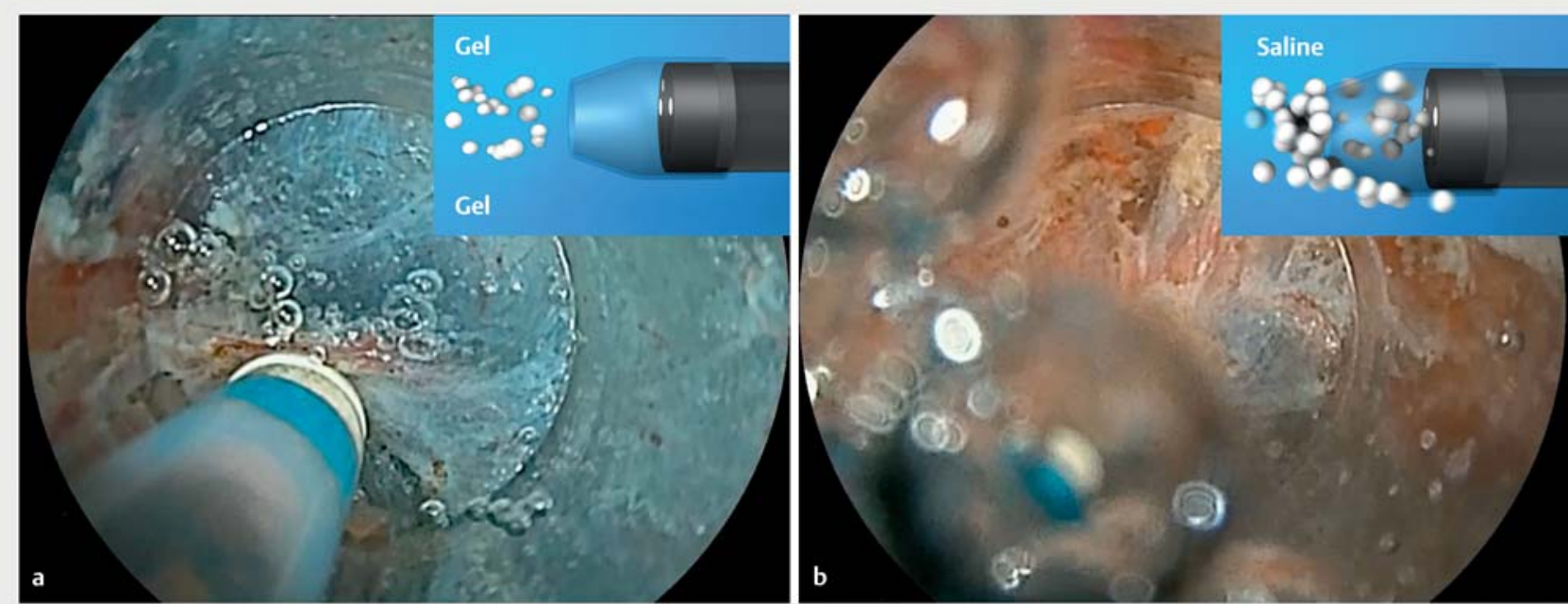

-Fig. 2 Differences between saline and gel immersion during the pocket-creation method of endoscopic submucosal dissection. The viscous characteristic of the gel (left) prevents the direct flow of gas bubbles into the tip of the hood, and bubbles can be removed easily by injecting a small amount of gel.

The authors

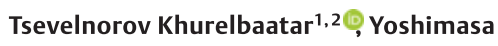
Miura ${ }^{1}$, Tomonori Yano ${ }^{1}{ }^{\oplus}$, Chihiro Iwashita ${ }^{1}$, Haruo Takahashi ${ }^{1}$, Alan Kawarai Lefor ${ }^{3}$, Hiroyuki Osawa', Hironori Yamamoto ${ }^{1 \odot}$

1 Department of Medicine, Division of Gastroenterology, Jichi Medical University, Tochigi, Japan

2 Department of Gastroenterology, Mongolian National University of Medical Sciences, Ulaanbaatar, Mongolia

3 Department of Surgery, Jichi Medical University, Tochigi, Japan

\section{Corresponding author}

\section{Tomonori Yano, MD, PhD}

Department of Medicine, Division of Gastroenterology, Jichi Medical University, 3311-1 Yakushiji, Shimotsuke, Tochigi, 329-0498, Japan tomonori@jichi.ac.jp

\section{References}

[1] Yano T, Nemoto D, Ono K et al. Gel immersion endoscopy: a novel method to secure the visual field during endoscopy in bleeding patients (with videos). Gastrointest Endosc 2016; 83: 809-811

[2] Yano T, Ohata A, Hiraki Y et al. Development of a gel dedicated to gel immersion endoscopy. Endosc Int Open 2021; 9: E918-E924

[3] Yamamoto H, Hayashi Y, Despott EJ. The pocket-creation method for endoscopic submucosal dissection combined with saline-immersion: another potential option to overcome challenges in colorectal endoscopic submucosal dissection. Gastrointest Endosc 2019; 90: 288-289

[4] Miura Y, Hayashi Y, Lefor AK et al. The pocket-creation method of ESD for gastric neoplasms. Gastrointest Endosc 2016; 83: 457-458

[5] Miura Y, Yano T, Takezawa T et al. Gel immersion endoscopy simplifies hemostasis during endoscopic submucosal dissection using the pocket-creation method. Endoscopy 2018; 50: E294-E295

\section{Bibliography}

Endoscopy 2022; 54: E512-E513

DOI $10.1055 / \mathrm{a}-1559-1863$

ISSN 0013-726X

published online 15.10 .2021

(c) 2021. Thieme. All rights reserved.

Georg Thieme Verlag KG, Rüdigerstraße 14,

70469 Stuttgart, Germany

\section{ENDOSCOPY E-VIDEOS}

https://eref.thieme.de/e-videos

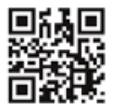

Endoscopy E-Videos is an open access online section, reporting on interesting cases and new techniques in gastroenterological endoscopy. All papers include a high quality video and all contributions are freely accessible online. Processing charges apply (currently EUR 375), discounts and wavers acc. to HINARI are available.

This section has its own submission website at

https://mc.manuscriptcentral.com/e-videos 